\title{
Comparison of efficacy and safety of two starting insulin regimens in non-Asian, Asian Indian, and East Asian patients with type 2 diabetes: a post hoc analysis of the PARADIGM study
}

\author{
This article was published in the following Dove Press journal: \\ Diabetes, Metabolic Syndrome and Obesity:Targets and Therapy \\ 9 August 2016 \\ Number of times this article has been viewed
}

\section{Linong Ji' \\ Kyung Wan Min² \\ Juliana Oliveira ${ }^{3}$ \\ Thomas Lew ${ }^{4}$ \\ Ran Duan ${ }^{3}$}

'Department of Endocrinology, Peking University People's Hospital, Beijing, People's Republic of China; ${ }^{2}$ Department of Endocrinology, Eulji Hospital, Seoul, Republic of Korea; ${ }^{3}$ Eli Lilly and Company, Indianapolis, IN, USA; ${ }^{4}$ Eli Lilly and Company, Taipei, Songshan District, Taiwan

\section{Video abstract}

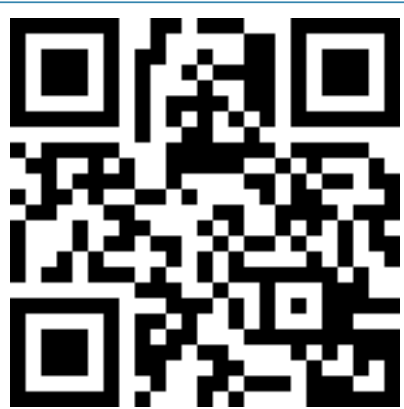

Point your SmartPhone at the code above. If you have a QR code reader the video abstract will appear. Or use: http://youtu.be/GrbmelZa3NO

Correspondence:Thomas Lew Eli Lilly and Company, I I th floor, 365 Fuxing North Road, Taipei 10543 , Songshan District, Taiwan Tel +886235182213

Email lew_thomas@lilly.com

Objective: The objective of this study was to explore the efficacy and safety of insulin lispro mix 25 (25\% insulin lispro and 75\% insulin lispro protamine suspension [LM25]) or insulin glargine plus insulin lispro $(\mathrm{G}+\mathrm{L})$ in insulin-naïve patients with type 2 diabetes from different racial/ethnic groups.

Methods: Three subgroups from the PARADIGM study were analyzed post hoc: non-Asian $(\mathrm{n}=130)$, Asian Indian ( $\mathrm{n}=106)$, and East Asian $(\mathrm{n}=89)$.

Results: All subgroups recorded glycated hemoglobin $\left(\mathrm{HbA}_{1 \mathrm{c}}\right)$ reductions: non-Asian (LM25, -2.07\%; G+L , -2.05\%), Asian Indian (LM25, -1.75\%; G+L, -1.60\%), and East Asian (LM25, -2.03\%; G+L, -1.76\%); end point $\mathrm{HbA}_{1 \mathrm{c}}$ values were higher in Asian Indians and East Asians than in non-Asians. Fewer Asian Indians (LM25, 43.2\%; G+L, 29.2\%) and East Asians (LM25, 37.5\%; G+L, 36.1\%) reached $\mathrm{HbA}_{1 \mathrm{c}}<7 \%$ versus non-Asians (LM25, 51.7\%; G+L, $48.1 \%$ ); differences were not significant ( $P=0.12$ and $P=0.06$, respectively). The mean total daily insulin dose $(\mathrm{U} / \mathrm{kg})$ for non-Asians was $0.67(\mathrm{LM} 25)$ and $0.61(\mathrm{G}+\mathrm{L})$, for Asian Indians was $0.91(\mathrm{LM} 25)$ and $0.90(\mathrm{G}+\mathrm{L})$, and for East Asians was $0.53(\mathrm{LM} 25)$ and $0.59(\mathrm{G}+\mathrm{L})$. The ratio of mealtime to total insulin dose in the $\mathrm{G}+\mathrm{L}$ arm for non-Asians was $0.19 \pm 0.23$, for Asian Indians was $0.33 \pm 0.25$, and for East Asians was $0.34 \pm 0.27$. Overall incidence (\%) of hypoglycemia in non-Asians was 94.1 (LM25) and $91.8(\mathrm{G}+\mathrm{L})$, in Asian Indians was 90.4 (LM25) and $88.5(\mathrm{G}+\mathrm{L})$, and in East Asians was 69.8 (LM25) and $77.3(\mathrm{G}+\mathrm{L})$.

Conclusion: Asian Indians showed least improvement in glycemic $\mathrm{HbA}_{1 \mathrm{c}}$ reduction despite greater insulin use. East Asians and non-Asians achieved similar $\mathrm{HbA}_{1 \mathrm{c}}$ reduction in the LM25 arm with a lower rate of hypoglycemia. Asians required more mealtime insulin coverage than non-Asians. This study added important insight into the effect of ethnicity on insulin treatment outcomes in patients with type 2 diabetes.

Keywords: ethnicity, insulin, race, type 2 diabetes mellitus

\section{Introduction}

Type 2 diabetes is a global health problem known to disproportionately affect specific racial and ethnic groups that have significant differences in metabolic responses to insulin therapy. ${ }^{1-3}$

Among Asian countries, India and the People's Republic of China have the highest number of type 2 diabetes patients in the world., ${ }^{2,4}$ Type 2 diabetes tends to develop at a younger age and progresses faster in Asian patients than in other populations. ${ }^{6}$ In addition, higher postprandial glucose levels have been reported in Asians., ${ }^{4,7}$ 
Asians have a higher daily intake of carbohydrates and, when compared to other ethnic groups, ${ }^{8}$ also show higher glycemic responses to the same glycemic load compared to non-Asian subjects. ${ }^{7}$ Ethnicity is therefore an important consideration in the contribution of postprandial glucose to glycated hemoglobin $\left(\mathrm{HbA}_{1 \mathrm{c}}\right)$.

The "metabolically obese" phenotype despite normal weight has already been described in Asian Indian ethnic people. ${ }^{2,4,6,9,10}$ Compared to non-Asian patients, these Asian Indians have been shown to have a significantly lower body mass index (BMI) cutoff value ( $\left.\geq 23 \mathrm{~kg} / \mathrm{m}^{2}\right)$, after which the risk for diabetes increases progressively. ${ }^{11}$

Despite the apparent phenotypic and possible pathophysiologic differences in type 2 diabetes among races/ ethnicities, ${ }^{3,12}$ few insulin clinical trials have examined the effect of race/ethnicity with regard to both Asian and nonAsian populations on treatment outcomes within one study. The PARADIGM study enrolled a diverse cohort of patients from multiple countries and different racial/ethnic backgrounds. The primary objective was to test, in patients with type 2 diabetes inadequately controlled with oral antidiabetic medications, whether initiation and intensification with insulin lispro mix 25 (25\% insulin lispro and 75\% insulin lispro protamine suspension [LM25]) therapy was noninferior to initiation and intensification with insulin glargine plus insulin lispro $(\mathrm{G}+\mathrm{L})$ therapy, in terms of glycemic control. ${ }^{13}$

The objective of this post hoc analysis of the PARADIGM study was to explore differences between non-Asian, Asian Indian, and East Asian type 2 diabetic patients with respect to initiation and intensification of insulin therapy with insulin LM25 compared with G+L.

\section{Methods}

\section{Study design}

This manuscript is the result of a post hoc analysis of data from the PARADIGM study (NCT 00548808). A detailed description of the PARADIGM study design has been previously published. ${ }^{13}$ Briefly, the randomized, multicountry, open-label, active-controlled study enrolled male and female insulin-naïve patients with type 2 diabetes with inadequate glycemic control $\left(\mathrm{HbA}_{1 \mathrm{c}} \geq 7.0 \%[\geq 53 \mathrm{mmol} / \mathrm{mol}]\right.$ and $<11.0 \%[<97 \mathrm{mmol} / \mathrm{mol}]$ ) while taking oral antidiabetic medications (metformin plus sulfonylurea and/or pioglitazone) without insulin for at least 90 days.

Eligible patients, aged 30-80 years, were randomly assigned to either LM25 treatment (one daily LM25 injection and progressing up to three daily injections) or $\mathrm{G}+\mathrm{L}$ treatment (one daily glargine injection and progressing up to three additional daily lispro injections). Patients were stratified by country, $\mathrm{HbA}_{1 \mathrm{c}}(\leq 8.5 \%$ and $>8.5 \%$ ), and continuing use of a sulfonylurea. The insulin intensification process has been previously described. ${ }^{13}$ Briefly, patients initiated insulin therapy with either one 10-U injection of LM25 (administered within 15 minutes prior to the evening meal) or with one $10-\mathrm{U}$ injection of insulin glargine (administered at bedtime). Doses could be adjusted by the patients at any time during the study according to the specified dosing algorithm for each treatment, and adjustments were based on premeal blood glucose measurements. Investigators assessed patient-made dose adjustments at least weekly for the first 8 weeks and then at least once every 2 weeks until the end of the study. Patients were encouraged by the investigators to establish a stable insulin dose (at least 4 weeks) and lower blood glucose values to near target before adding an additional injection.

All patients needed to be receptive to diabetes education (as per routine practice), including continuing their prestudy diet and activity levels or following simple dietary advice as appropriate. At visit 2, study personnel also reinforced dietary instructions and provided training on blood glucose monitoring.

The PARADIGM study was conducted in accordance with the International Conference on Harmonisation Guidelines for Good Clinical Practice and the Declaration of Helsinki as well as the following Health Authorities approved the protocol: State Food and Drug Administration (People's Republic of China); Indian Council of Medical Research (India); Individual site Institutional Review Boards (Republic of Korea). All patients provided written informed consent.

This subanalysis focused on three racial/ethnic subgroups: non-Asian ( $\mathrm{n}=130$ ), represented by patients recruited in Australia, Brazil, Canada, and Mexico; Asian Indian $(n=106)$, represented by patients recruited in India; and East Asian ( $n=89$ ), represented by patients recruited in the People's Republic of China and South Korea. There were no patients of Asian ethnicity enrolled in non-Asian countries.

\section{Statistical methods}

All analyses for the non-Asian, Asian Indian, and East Asian subgroups were conducted using the full analysis set, which included patients who received at least one dose of study drug. The study end point was defined as the last patient visit after completing $\geq 32$ weeks of study treatment.

The $\mathrm{HbA}_{1 \mathrm{c}}$ changes from baseline for each subgroup were analyzed using a mixed model for repeated measure analysis that had baseline $\mathrm{HbA}_{1 \mathrm{c}}$, treatment, subgroup, 
Table I Baseline demographics and characteristics (full analysis set)

\begin{tabular}{|c|c|c|c|c|c|c|}
\hline & \multicolumn{2}{|l|}{ Non-Asian } & \multicolumn{2}{|l|}{ Asian Indian } & \multicolumn{2}{|l|}{ East Asian } \\
\hline & $\operatorname{LM25}(n=69)$ & $\mathbf{G}+\mathbf{L}(\mathbf{n}=61)$ & $\operatorname{LM25}(n=53)$ & $\mathbf{G}+\mathbf{L}(n=53)$ & LM25 (n=45) & $G+L(n=44)$ \\
\hline Mean age $(\mathrm{SD})$, years & $58.62(8.67)$ & $61.67(8.45)$ & $55.15(8.22)$ & $53.11(8.62)$ & $57.20(7.62)$ & $54.36(9.07)$ \\
\hline Female sex, n (\%) & $27(39.1)$ & $24(39.3)$ & $28(52.8)$ & $28(52.8)$ & $30(66.7)$ & $24(54.5)$ \\
\hline Mean duration of diabetes (SD), years & $|2.6|(6.52)$ & $10.63(6.32)$ & $9.51(6.88)$ & $8.54(4.4 I)$ & $10.03(5.02)$ & $9.40(4.43)$ \\
\hline Mean body weight (SD), kg & $84.03(18.02)$ & $82.12(14.82)$ & $65.96(10.6 I)$ & $67.90(10.18)$ & $67.79(10.88)$ & $65.69(10.37)$ \\
\hline Mean BMI (SD), kg/m² & $29.56(4.02)$ & $29.14(3.82)$ & $26.09(3.54)$ & $26.60(3.87)$ & $25.62(3.15)$ & $24.92(2.8 I)$ \\
\hline Mean $\mathrm{HbA}_{\mathrm{Ic}}(\mathrm{SD}), \%$ & $8.93(1.02)$ & $8.85(1.01)$ & $9.22(1.09)$ & $9.29(1.00)$ & $8.87(0.92)$ & $8.82(1.08)$ \\
\hline Sulfonylurea use, $\mathrm{n}(\%)^{\mathrm{a}}$ & $69(100.0)$ & $61(100.0)$ & $53(100.0)$ & $53(100.0)$ & $42(93.3)$ & $42(95.5)$ \\
\hline
\end{tabular}

Note: at baseline, all patients in the full analysis set were on metformin.

Abbreviations: LM25, insulin lispro mix 25 (25\% insulin lispro and $75 \%$ insulin lispro protamine suspension); G+L, glargine plus lispro; BMI, body mass index; HbA hemoglobin.

sulfonylurea use, visit, and treatment-by-visit interaction as fixed effects and patient as a random effect. By using baseline information and treatment as covariates in the mixed model for repeated measure analysis, the comparison between the three regions is adjusted for any baseline differences and any treatment effects. The least-squares means of change from baseline and $P$-values from Type III sums of squares were produced. Glucose excursions were analyzed for each subgroup using analysis of covariance (ANCOVA) that had baseline glucose excursion, treatment, subgroup, and treatment-by-subgroup as covariates. Any multiple comparisons between two regions were conducted using the Tukey's test.

The $\mathrm{HbA}_{1 \mathrm{c}}$ targets for each subgroup were analyzed using a generalized estimating equations model for logistic regression with fixed effects of baseline $\mathrm{HbA}_{1 \mathrm{c}}$ stratum, treatment, sulfonylurea use, visit, and treatment-by-visit interaction. The percentages of patients reaching the target of $\mathrm{HbA}_{1 \mathrm{c}}<7 \%$ are reported. Baseline demographics, insulin dose/number of injection, mean weight change, and rate of hypoglycemia are expressed as mean and SD for continuous variables and percentage for categorical variables. $\mathrm{HbA}_{1 \mathrm{c}}$ values are shown as National Glycohemoglobin Standardization Program values.

All analyses were conducted using SAS 9.2 (SAS Institute Inc., Cary, NC, USA). Statistically significant differences between subgroups were not determined due to a lack of statistical power in the relatively small subgroups.

\section{Results}

\section{Baseline characteristics}

Baseline characteristics were generally similar among nonAsian, Asian Indian, and East Asian patients (Table 1). All non-Asian and East Asian patients were taking metformin and a sulfonylurea at baseline, whereas a small percentage of Asian Indian patients were not taking any sulfonylurea at baseline.

\section{$\mathrm{HbA}$}

There was a significant decrease from baseline $\mathrm{HbA}_{1 \mathrm{c}}$ at the end point in all three groups $(P<0.001)$. At the end point, numerical values for $\mathrm{HbA}_{1 \mathrm{c}}$ were higher in Asian

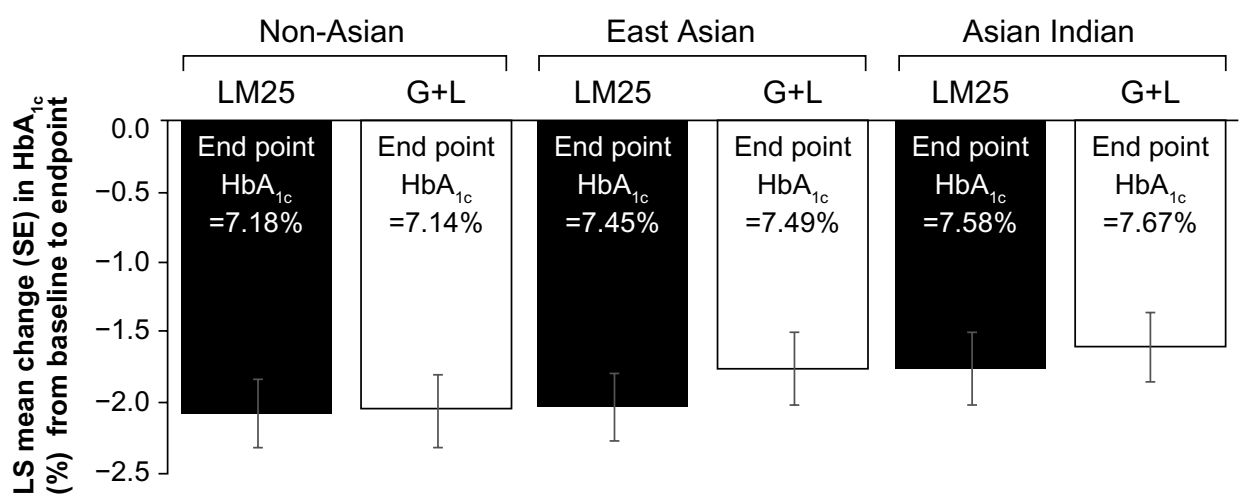

Figure I LS mean change (SE of mean) in $\mathrm{HbA}_{\mathrm{Ic}}$ from baseline to the end point.

Abbreviations: LS, least-squares; SE, standard error; $\mathrm{HbA}_{\mathrm{Ic}}$, glycated hemoglobin; LM25, insulin lispro mix 25 ( $25 \%$ insulin lispro and $75 \%$ insulin lispro protamine suspension); $\mathrm{G}+\mathrm{L}$, glargine plus lispro. 


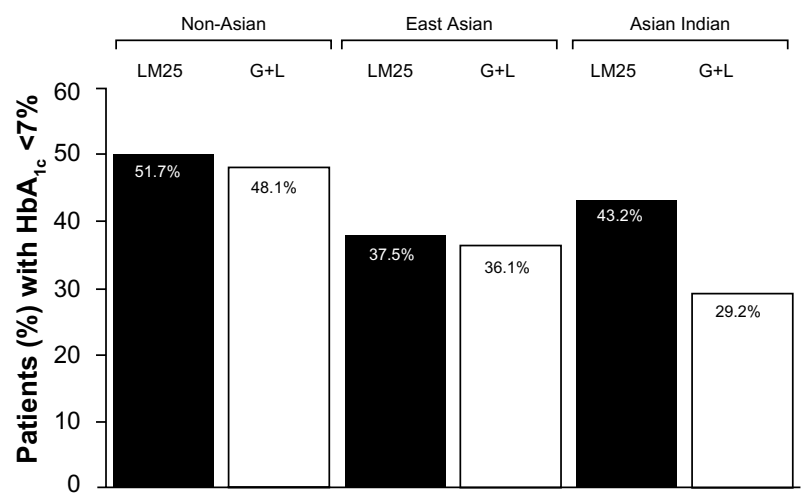

Figure 2 Percentage of patients achieving $\mathrm{HbA}_{\mathrm{lc}}$ target $<7 \%$ at the end point by race/ethnicity and by treatment arm.

Abbreviations: $\mathrm{HbA}_{1 \mathrm{c}}$, glycated hemoglobin; LM25, insulin lispro mix 25 (25\% insulin lispro and $75 \%$ insulin lispro protamine suspension); G+L, glargine plus lispro.

Indian and East Asian patients compared with non-Asian patients, although the differences between the groups in change in $\mathrm{HbA}_{1 \mathrm{c}}$ were not statistically significant (Figure 1). Changes (least-squares mean \pm standard error) in $\mathrm{HbA}_{1 \mathrm{c}}$ from baseline to the end point were as follows: non-Asian (LM25, -2.07 $\pm 0.24 ; \mathrm{G}+\mathrm{L},-2.05 \pm 0.24)$, Asian Indian (LM25, $-1.75 \pm 0.25 ; \mathrm{G}+\mathrm{L},-1.60 \pm 0.25)$, and East Asian (LM25, -2.03 $\pm 0.24 ; \mathrm{G}+\mathrm{L},-1.76 \pm 0.24)$.

At the end point, the percentage of Asian Indian (LM25, 43.2\%; G+L, 29.2\%) and East Asian (LM25, 37.5\%; G+L, $36.1 \%$ ) patients reaching the $\mathrm{HbA}_{1 \mathrm{c}}$ target $(<7 \%)$ was numerically but not statistically lower than the percentage of non-Asian patients reaching the target (LM25, 51.7\%; $\mathrm{G}+\mathrm{L}, 48.1 \%$; Figure 2).

\section{Insulin dose}

The mean daily insulin dose at the end point and ratio of mealtime to total insulin dose for each subgroup are shown in Table 2. The mean number of injections per day was approximately two in each group. More than half of the Asian Indian population required three or four injections in either treatment arm (LM25, 56.6\%; G+L, 58.5\%). More than $80 \%$ of the non-Asian $(82.6 \%)$ and East Asian $(82.2 \%)$ populations required two or fewer injections in the LM25 arm. In the $\mathrm{G}+\mathrm{L}$ arm, $59 \%, 43.2 \%$, and $32 \%$ of the non-Asian, East Asian, and Asian Indian populations, respectively, stayed on basal-only treatment. More than half of both Asian populations (Asian Indians: 58.4\%, East Asians: $52.2 \%$ ) in contrast to $29.5 \%$ of non-Asians in the $\mathrm{G}+\mathrm{L}$ arm needed mealtime insulin coverage for at least two meals.

\section{Blood glucose}

At baseline, East Asians generally had numerically higher glucose excursion values compared to the other two populations, regardless of the type of meal. The improvement in glucose excursion was generally greatest in East Asians among the three populations at each meal. At breakfast, East Asians showed significant $(P<0.05)$ glucose excursion improvement in both the LM25 and G+L treatment arms compared to Asian Indians. Non-Asians also showed significantly greater improvement in glucose excursion during breakfast in the LM25 treatment arm compared to Asian Indians (Table 3). At lunch, both Asian populations

Table 2 Insulin dose/number of injections, weight change, and hypoglycemia rate

\begin{tabular}{|c|c|c|c|c|c|c|}
\hline & \multicolumn{2}{|l|}{ Non-Asian } & \multicolumn{2}{|l|}{ Asian Indian } & \multicolumn{2}{|l|}{ East Asian } \\
\hline & LM25 $(n=69)$ & $\mathbf{G}+\mathbf{L}(n=61)$ & LM25 (n=53) & $\mathbf{G}+\mathbf{L}(\mathbf{n}=\mathbf{5 3})$ & $\operatorname{LM} 25(n=45)$ & $\mathbf{G}+\mathbf{L}(\mathrm{n}=\mathbf{4 4})$ \\
\hline Mean daily insulin dose/kg (SD) & $0.569(0.370)$ & $0.496(0.366)$ & $0.80 I(0.500)$ & $0.853(0.681)$ & $0.422(0.37 I)$ & $0.464(0.368)$ \\
\hline Total mean insulin dose (SD) & $60.228(34.156)$ & $52.769(39.924)$ & 61.659 (33.559) & $63.340(33.723)$ & $37.468(17.255)$ & 40.971 (26.297) \\
\hline Basal insulin dose (SD) & 45.171 & $36.596(20.859)$ & 46.244 & $36.340(12.310)$ & 28.101 & $23.37 \mid(12.868)$ \\
\hline Prandial insulin dose (SD) & 15.057 & I6. 173 (24.059) & $15.4 \mid 5$ & $27.000(26.438)$ & 9.367 & I 7.600 (| 8.039$)$ \\
\hline Prandial dose/total dose (SD) & & $0.188(0.232)$ & & $0.325(0.254)$ & & $0.342(0.273)$ \\
\hline Mean number of injections & 1.942 & 1.934 & 2.320 & 2.434 & 1.756 & 2.386 \\
\hline \multicolumn{7}{|l|}{ Number of injections } \\
\hline One, n (\%) & $16(23.2)$ & 36 (59) & $13(24.5)$ & $17(32)$ & $19(42.2)$ & $19(43.2)$ \\
\hline Two, n (\%) & $4 I(59.4)$ & $7(|| .5)$ & $10(18.8)$ & $5(9.4)$ & $18(40.0)$ & $2(4.5)$ \\
\hline Three, n (\%) & $12(17.4)$ & $4(6.6)$ & $30(56.6)$ & $22(4 \mid .5)$ & $8(17.7)$ & $10(22.7)$ \\
\hline Four, n (\%) & - & 14 (22.9) & - & $9(16.9)$ & - & $13(29.5)$ \\
\hline Mean weight change (SD), kg & $3.00(4.09)$ & $3.43(4.72)$ & $3.19(3.87)$ & $2.82(3.42)$ & $2.95(2.97)$ & $2.81(3.39)$ \\
\hline Hypoglycemia rate, ${ }^{a}$ mean (SD) & $3.292(3.082)$ & $2.992(2.798)$ & I.II0 (1.007) & $1.482(2.122)$ & $1.266(1.617)$ & $0.857(0.797)$ \\
\hline Overall hypoglycemia, n (\%) & $64(94.1)$ & $56(91.8)$ & $47(90.4)$ & $46(88.5)$ & $30(69.8)$ & $34(77.3)$ \\
\hline Nocturnal hypoglycemia, n (\%) & $57(83.8)$ & $48(78.7)$ & $42(80.8)$ & $45(86.5)$ & 18 (4I.9) & $23(52.3)$ \\
\hline Severe hypoglycemia, n (\%) & $2(2.9)$ & $3(4.9)$ & $2(3.9)$ & I (I.9) & $3(7.0)$ & $0(0.0)$ \\
\hline
\end{tabular}

Note: aHypoglycemia rate was defined as event/patient/month.

Abbreviations: LM25, insulin lispro mix 25 ( $25 \%$ insulin and $75 \%$ insulin lispro protamine suspension); G+L, glargine plus lispro. 
Table 3 Self-monitored blood glucose profile - actual measurements ( $\mathrm{mmol} / \mathrm{L}$; excursion change from baseline)

\begin{tabular}{|c|c|c|c|c|c|}
\hline & & & $\begin{array}{l}\text { Baseline excursion before } \\
\text { and after meal glucose } \\
\text { difference, mean (SD) }\end{array}$ & $\begin{array}{l}\text { End point ( } \geq 32 \text { weeks) excursion } \\
\text { before and after meal glucose } \\
\text { difference, mean (SD) }\end{array}$ & $\begin{array}{l}\text { Change in excursion between } \\
\text { baseline and end point ( } \geq 32 \\
\text { weeks), mean (SD) }\end{array}$ \\
\hline \multirow[t]{6}{*}{ Breakfast } & Non-Asian & LM25 & $3.735(2.434)$ & I.855 (2.096) & $-1.964(2.637)$ \\
\hline & & $\mathrm{G}+\mathrm{L}$ & $3.969(2.421)$ & $2.680(1.993)$ & $-1.246(2.795)$ \\
\hline & Asian Indian & LM25 & $3.314(2.567)$ & $2.467(1.435)$ & $-0.74 \mathrm{I}(2.664)^{*}$ \\
\hline & & $\mathrm{G}+\mathrm{L}$ & 3.347 (2.719) & 2.795 (1.919) & $-0.393(2.634)$ \\
\hline & East Asian & LM25 & $4.976(2.456)$ & $2.978(2.042)$ & $-2.323(2.949)^{* k}$ \\
\hline & & $\mathrm{G}+\mathrm{L}$ & $5.174(2.728)$ & $2.872(2.55 \mathrm{I})$ & $-2.214(3.252)^{* k *}$ \\
\hline \multirow[t]{6}{*}{ Lunch } & Non-Asian & LM25 & I. $240(2.636)$ & $2.030(2.532)$ & $0.918(2.857)$ \\
\hline & & $\mathrm{G}+\mathrm{L}$ & $1.568(2.244)$ & $1.082(2.116)$ & $-0.274(3.077)$ \\
\hline & Asian Indian & LM25 & $2.923(2.704)$ & $2.517(1.612)$ & $-0.444(3.148)^{*}$ \\
\hline & & $\mathrm{G}+\mathrm{L}$ & $2.373(3.296)$ & $2.324(1.773)$ & $-0.062(3.604)$ \\
\hline & East Asian & LM25 & 3.614 (2.599) & $3.130(2.336)$ & $-0.817(3.185)^{k 0 k p k}$ \\
\hline & & $\mathrm{G}+\mathrm{L}$ & $3.199(2.964)$ & $1.967(1.77)$ & $-0.928(2.506)$ \\
\hline \multirow[t]{6}{*}{ Dinner } & Non-Asian & LM25 & I.68I (2.7I $)$ & 0.854 (1.999) & $-0.968(2.708)$ \\
\hline & & $\mathrm{G}+\mathrm{L}$ & $2.038(2.574)$ & 1.496 (2.259) & $-0.635(3.358)$ \\
\hline & Asian Indian & LM25 & $2.296(2.912)$ & $2.363(1.654)$ & $-0.173(3.214)$ \\
\hline & & $\mathrm{G}+\mathrm{L}$ & $2.605(2.785)$ & 2.381 (1.930) & $-0.192(3.160)$ \\
\hline & East Asian & LM25 & 3.177 (2.977) & I.588 (2.72I) & $-1.606(3.224)$ \\
\hline & & $\mathrm{G}+\mathrm{L}$ & $2.5 \mid 7(2.8 \mid 3)$ & I.37I (2.644) & $-1.416(3.479)$ \\
\hline
\end{tabular}

Notes: *Significant $(P<0.05)$ difference between Asian Indian and non-Asian. **Significant $(P<0.05)$ difference between East Asian and Asian Indian. ***Significant $(P<0.05)$ difference between East Asian and non-Asian.

Abbreviations: LM25, insulin lispro mix 25 (25\% insulin and 75\% insulin lispro protamine suspension); G+L, glargine plus lispro.

showed significantly better glycemic excursion improvement compared to the non-Asians. At dinner, excursion values were higher for East Asians than Asian Indians and non-Asians, although the difference was not statistically significant.

\section{Body weight}

The mean change in body weight $(\mathrm{kg})$ for each subgroup is shown in Table 2.

\section{Hypoglycemia}

The hypoglycemia rate and overall incidence of hypoglycemia at the end point were higher in the non-Asian group than in the Asian Indian or East Asian group (Table 2).

\section{Discussion}

Although both regimens in the PARADIGM study resulted in significant improvement in $\mathrm{HbA}_{1 \mathrm{c}}$, compared to baseline, at the end point, there was a trend toward higher $\mathrm{HbA}_{1 c}$ values and lower percentages of patients reaching $\mathrm{HbA}_{1 \mathrm{c}}$ targets in East Asian and Asian Indian patients compared with nonAsian patients. These results might be explained by more caution in increasing insulin dose in the East Asian group, as a result of higher concern about hypoglycemia. However, based on the results of this subanalysis, it may be that other factors like increases in insulin resistance in the Asian Indian population might have also played a role..$^{14}$
Notwithstanding the A1chieve study, which studied 16,823 insulin-naïve patients from India, ${ }^{15}$ few studies have examined the effect of race/ethnicity, particularly with respect to Asians, on treatment outcomes of type 2 diabetes in insulin clinical trials. Although multiple studies evaluating diabetes treatment in East Asians have been conducted, ${ }^{16,17}$ few studies have involved patients of Asian Indian origin. The prevalence of diabetes and impaired glucose tolerance is high for all Asian countries and is increasing exponentially. ${ }^{2,18}$ Asians develop diabetes at a younger age and lower BMI compared with their Western counterparts. ${ }^{2,18}$ Studies have suggested that Asians are genetically more susceptible to type 2 diabetes compared with non-Asians, which could be due to earlier beta cell dysfunction in Asians. ${ }^{419}$ In this study, in East Asians compared with non-Asians and Asian Indians, there was a trend for less overall hypoglycemia, in particular nocturnal hypoglycemia, although these trends were not statistically significant. The lower incidence of hypoglycemia in the Asian subgroups is likely the result of less aggressive insulin titration, as shown by fewer patients reaching the $\mathrm{HbA}_{1 \mathrm{c}}$ target of $<7 \%$ in both Asian subgroups. Alternatively, this difference may be due to regional differences in the rate of reporting hypoglycemia.

All three populations assessed in the current study, despite having various degrees of glycemic excursion, showed the highest glucose excursion of the day during breakfast, possibly 
due to the dawn phenomenon, in which counter-regulatory hormones are excreted that result in higher insulin resistance or the effect of the exogenous insulin administered to the patient the day before disappears. East Asians have higher glucose excursion throughout the day at baseline compared to the other subpopulations, and the improvement of glucose excursion was also numerically larger compared to the other populations in either treatment arm. Among the three populations, Asian Indians in general showed the least improvement in glycemic excursion, despite having a similar mealtime insulin ratio and a higher dose of insulin compared to East Asians. Of the three populations, non-Asians had the greatest proportion of patients staying on basal-only therapy and also the highest proportion of patients able to stay on two or fewer injections in the $\mathrm{G}+\mathrm{L}$ arm, contributing to the hypothesis that non-Asians have better insulin secretion capacity to overcome mealtime needs with adequate fasting glucose control. Approximately $80 \%$ of subjects in the East Asian and non-Asian populations stayed at two or fewer injections in the premixed treatment arm. In contrast, more than half of the patients in the Asian Indian population required three LM25 insulin injections. Improvement in glucose excursion was seen in the non-Asian group compared to the Asian Indian group at breakfast and dinner but the reverse was seen at lunch, probably due to fewer non-Asian subjects covered by mealtime insulin at lunch from the LM25 arm. Despite similar percentages using two daily injections of LM25, East Asians showed persistent improvement in glucose excursion for all three meals. In general, Asian Indians received a higher total insulin dose, but still showed a relatively lower $\mathrm{HbA}_{1 \mathrm{c}}$ reduction compared to non-Asians or East Asians. Both Asian populations showed higher prandial-to-total insulin dose ratios compared to non-Asians. These results may be related to an inadequate beta cell response to increasing insulin resistance. Multiethnic studies have highlighted that for any given BMI or waist circumference, Asians have greater adiposity or visceral fat than Caucasians..$^{20}$ An Asian diet that is rich in carbohydrates may also be a contributing factor, combined with a relatively weaker insulin secretory capacity by the beta cell. Despite having a similar pattern of basal and mealtime insulin ratio to that of East Asians, Asian Indians improved less in glycemic excursion on both treatment arms. The need for greater insulin dose suggests that Asian Indians may have even higher insulin resistance, as noted in previously published studies, ${ }^{21}$ perhaps from a genetic and dietary perspective.

Insulin resistance seems to play an important role in the development of type 2 diabetes in non-Asians, whereas beta cell dysfunction and decreased insulin secretion may be more prominent in Asians. ${ }^{19}$ Therefore, East Asians may respond better with insulin replacement and have a greater need for mealtime insulin as a result of faster, earlier deterioration of insulin secretory capacity, which was the finding in this subanalysis. East Asians with less insulin secretory capacity would be less likely to respond to only basal insulin, as their insulin secretory response to meal or glucose challenge may be inadequate. In contrast, non-Asians, with potentially better beta cell residual function, would be more likely to achieve glycemic control on basal coverage..$^{20,22}$

There are limitations to the current analysis. The PARADIGM study was not specifically designed to assess the impact of race/ethnicity on treatment. Also, the study design was open label due to the different appearances of the insulin preparations. Insulin titration was not a forced process, allowing room for the investigator's discretion; therefore, there may have been some influence of local differences in treatment intensification in clinical practices in the various countries. In addition, it was not possible to adequately control cultural factors (eg, diet and exercise, access to medical care, socioeconomic factors, and patient adherence to medical treatment). Although the numbers in each treatment group are lower than in the original study, ${ }^{13}$ group numbers were relatively even in each of the subgroups of this study. We were unable to determine statistical differences between the subgroups due to a lack of statistical power, since this exploratory subgroup analysis was not designed or powered to show significance in subgroups, in which relatively small sample sizes make accurate inferences challenging. Differences between the subgroups in digestible versus nondigestible quantities of carbohydrates in meals were not investigated in this analysis. Nonetheless, strengths of this study are that patients of both Asian and non-Asian origin participated, the same protocol and same treatments were used, and the key end points were centrally measured. An additional strength of this analysis is the separation of Asian patients into Asian Indian and East Asian groups.

\section{Conclusion}

Some numerical differences in glycemic control and insulin doses were observed between non-Asian, Asian Indian, and East Asian patients in the PARADIGM study of patients with type 2 diabetes initiating insulin. The findings of this subanalysis suggest a greater need for mealtime insulin among Asian patients, which may be reflective of a lower insulin secretory capacity combined with a greater insulin resistance due to higher visceral fat combined with a diet high 
in carbohydrate. In addition, there may be also a difference between Indians and Asians of Eastern origin, in which insulin resistance may play a greater role in the Asian Indian population than in Eastern Asians. These findings, although exploratory, add to the growing body of literature describing potential racial/ethnic differences among patients with type 2 diabetes and highlight the importance of considering race/ ethnicity when evaluating insulin treatment regimens for patients with type 2 diabetes.

\section{Acknowledgments}

Funding for this study was provided by Eli Lilly and Company. We thank Dan Blaukopf (inVentiv Health Clinical) for writing assistance.

\section{Disclosure}

Linong Ji has accepted lecturing and consulting fees from Eli Lilly and Company. Kyung Wan Min has no competing interests to disclose. Juliana Oliveira was an employee and shareholder of Eli Lilly and Company at the time this study was designed and implemented and is now an employee and shareholder of Takeda Pharmaceuticals. Thomas Lew and Ran Duan are employees of Eli Lilly and Company. The authors report no other conflicts of interest in this work.

\section{References}

1. International Diabetes Federation [webpage on the Internet]. IDF Diabetes Atlas. 6th ed. 2013. Available from: http://www.idf.org/sites/default/ files/EN_6E_Atlas_Full_0.pdf. Accessed November 6, 2015.

2. Ramachandran A, Ma RC, Snehalatha C. Diabetes in Asia. Lancet. 2010;375(9712):408-418.

3. Davidson JA, Lacaya LB, Jiang H, et al. Impact of race/ethnicity on the efficacy and safety of commonly used insulin regimens: a post hoc analysis of clinical trials in type 2 diabetes mellitus. Endocr Pract. 2010;16(5):818-828.

4. Chan JC, Malik V, Jia W, et al. Diabetes in Asia: epidemiology, risk factors, and pathophysiology. JAMA. 2009;301(20):2129-2140.

5. Wild S, Roglic G, Green A, Sicree R, King H. Global prevalence of diabetes: estimates for the year 2000 and projections for 2030. Diabetes Care. 2004;27(5):1047-1053.

6. Yoon KH, Lee JH, Kim JW, et al. Epidemic obesity and type 2 diabetes in Asia. Lancet. 2006;368(9548):1681-1688.

7. Dickinson S, Colagiuri S, Faramus E, Petocz P, Brand-Miller JC. Postprandial hyperglycemia and insulin sensitivity differ among lean young adults of different ethnicities. J Nutr. 2002;132(9):2574-2579.
8. Wang JS, Tu ST, Lee IT, et al. Contribution of postprandial glucose to excess hyperglycaemia in Asian type 2 diabetic patients using continuous glucose monitoring. Diabetes Metab Res Rev. 2011;27(1):79-84.

9. Raji A, Seely EW, Arky RA, Simonson DC. Body fat distribution and insulin resistance in healthy Asian Indians and Caucasians. $J$ Clin Endocrinol Metab. 2001;86(11):5366-5371.

10. Ramachandran A, Snehalatha C, Shetty AS, Nanditha A. Trends in prevalence of diabetes in Asian countries. World J Diabetes. 2012;3(6):110-117.

11. Snehalatha C, Viswanathan V, Ramachandran A. Cutoff values for normal anthropometric variables in Asian Indian adults. Diabetes Care. 2003;26(5):1380-1384.

12. Hu FB. Globalization of diabetes: the role of diet, lifestyle, and genes. Diabetes Care. 2011;34(6):1249-1257.

13. Bowering K, Reed VA, Felicio JS, Landry J, Ji L, Oliveira J. A study comparing insulin lispro mix 25 with glargine plus lispro therapy in patients with Type 2 diabetes who have inadequate glycaemic control on oral anti-hyperglycaemic medication: results of the PARADIGM study. Diabet Med. 2012;29(11):e263-e272.

14. Misra A, Vikram NK, Arya S, et al. High prevalence of insulin resistance in postpubertal Asian Indian children is associated with adverse truncal body fat patterning, abdominal adiposity and excess body fat. Int J Obes Relat Metab Disord. 2004;28(10):1217-1226.

15. Mohan V, Shah S, Saboo B. Current glycemic status and diabetes related complications among type 2 diabetes patients in India: data from the A1chieve study. J Assoc Physicians India. 2013;61(Suppl 1):12-15.

16. Ishii H, Terauchi Y, Jinnouchi H, Taketsuna M, Takeuchi M, Imaoka T. Effects of insulin changes on quality of life and glycemic control in Japanese patients with type 2 diabetes mellitus: the insulin-changing study intending to gain patients' insights into insulin treatment with patientreported health outcomes in actual clinical treatments (INSIGHTs) study. J Diab Invest. 2013;4(6):560-570.

17. Seino Y, Min KW, Niemoeller E, Takami A; EFC10887 GETGOAL-L Asia Study Investigators. Randomized, double-blind, placebo-controlled trial of the once-daily GLP-1 receptor agonist lixisenatide in Asian patients with type 2 diabetes insufficiently controlled on basal insulin with or without a sulfonylurea (GetGoal-L-Asia). Diabetes Obes Metab. 2012;14(10):910-917.

18. Ramachandran A, Snehalatha C, Vijay V. Low risk threshold for acquired diabetogenic factors in Asian Indians. Diabetes Res Clin Pract. 2004;65(3):189-195.

19. Staimez LR, Weber MB, Ranjani H, et al. Evidence of reduced $\beta$-cell function in Asian Indians with mild dysglycemia. Diabetes Care. 2013;36(9):2772-2778.

20. Ma RCW, Chan JCN. Type 2 diabetes in East Asians: similarities and differences with populations in Europe and the United States. Ann NY Acad Sci. 2013;1281:64-91.

21. Raji A, Gerhard-Herman MD, Warren M, et al. Insulin resistance and vascular dysfunction in nondiabetic Asian Indians. J Clin Endocrinol Metab. 2004;89(8):3965-3972.

22. Fukushima M, Suzuki H, Seino Y. Insulin secretion capacity in the development from normal glucose tolerance to type 2 diabetes. Diabetes Res Clin Pract. 2004;66(suppl 1):S37-S43.

Diabetes, Metabolic Syndrome and Obesity: Targets and Therapy

\section{Publish your work in this journal}

Diabetes, Metabolic Syndrome and Obesity: Targets and Therapy is an international, peer-reviewed open-access journal committed to the rapid publication of the latest laboratory and clinical findings in the fields of diabetes, metabolic syndrome and obesity research. Original research, review, case reports, hypothesis formation, expert opinion and commentaries are all considered for publication. The manuscript management system is completely online and includes a very quick and fair peer-review system, which is all easy to use. Visit $\mathrm{http} / / / \mathrm{www}$.dovepress.com/testimonials.php to read real quotes from published authors. 